\title{
ARCILLAS, ARENAS Y CERÁMICAS. EXPLORACIONES ARQUEOMÉTRICAS PARA EL ESTUDIO DE LASPRÁCTICAS ALFARERAS DEL NOROESTE ARGENTINO PREHISPÁNICO
}

\section{CLAYS, SANDS AND CERAMICS. ARCHAEOLOGICAL EXPLORATIONS FOR THE STUDY OF POTTERY PRACTICES OF THE PRE-HISPANIC ARGENTINE NORTHWEST}

\section{RESUMEN}

La tecnología cerámica de las sociedades que habitaron el sitio Tambería de Guandacol (La Rioja, Argentina), durante los últimos siglos prehispánicos (ca. XIII - XVII d. C.), se ha estudiado desde diferentes análisis arqueológicos convencionales, principalmente morfológicos, decorativos y de técnicas de manufactura. Asimismo, desde los análisis arqueométricos, se han realizado aportes vinculados especialmente a la tecnología de pastas cerámicas. El objetivo de este trabajo es contribuir al conocimiento sobre las propiedades y composición química y mineralógica de sedimentos arcillosos y arenosos del área de estudio y de cerámicas del sitio, buscando acercarse a diferentes etapas de la producción alfarera. Para ello se aplicaron los métodos analíticos: Difracción de Rayos X, Fluorescencia de Rayos X, Límites de Atterberg y microscopía petrográfica. El resultado principal de este estudio es la conformación de una base de datos químicos, litológicos y mineralógicos que permite comenzar a explorar la relación de la geología local con los restos cerámicos del área, así como discutir problemáticas vinculadas a la tecnología alfarera de las comunidades del área durante este extenso lapso, y proponer líneas de investigación futura.

Palabras clave: arqueología, tecnología cerámica, materia prima, Guandacol, Siglos XIIIXVII AD.

\section{ABSTRACT}

The pottery technology of the societies that inhabited the site Tambería de Guandacol (La Rioja, Argentina), during the last pre-Hispanic centuries (ca. XIII - XVII AD), has been studied from different traditional archaeological analyzes, mainly morphological, decorative and manufacturing techniques. Likewise, from archaeometric analysis, contributions have been made linked (especially to the technology of ceramic pastes. The objective of this work is to contribute to the knowledge about the properties and chemical, and mineralogical composition of clay and sandy sediments of the study area, and ceramics of the site, seeking to approach to the different pottery production stages. For this purpose, analytical methods were applied: $X$ ray diffraction, $X$-ray fluorescence, Atterberg Limits, and petrographic microscopy. The main result of this study is the conformation se of a chemical, lithological and mineralogical database that allows us to begin to explore the relationship of the local geology with the ceramic remains of the area, as well as to discuss problems related to the pottery technology of the communities of the area during this extensive period, and propose future research lines. Keywords: archaeology, pottery technology, raw materials, Guandacol, 13th - 17th century.
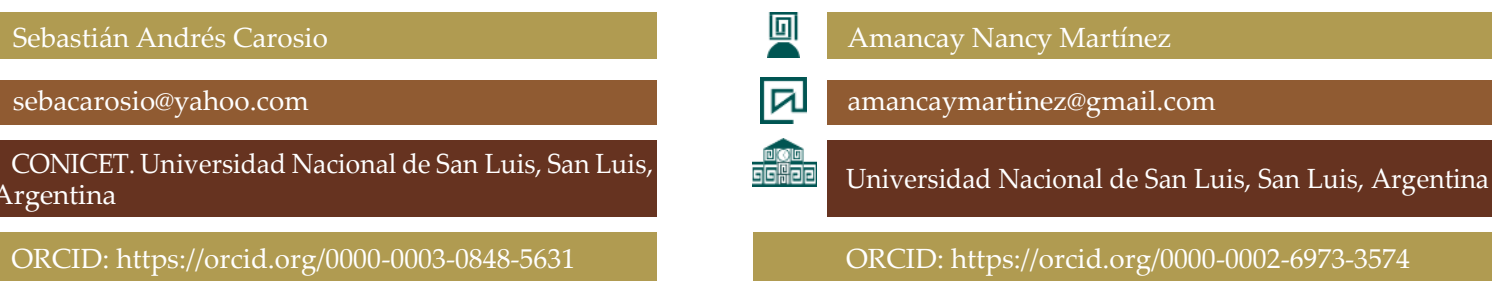


\section{INTRODUCCIÓN}

En Arqueología la alfarería originariamente ha sido utilizada como indicador cronológico, como fósil guía para la conformación de identidades étnicas, y para poner de manifiesto pautas de intercambio y relaciones sociales. Gracias a los aportes interdisciplinarios, los análisis cerámicos abarcan en la actualidad diferentes aspectos sociales, culturales, económicos y políticos (Rice 1987:3-4; Orton, Tyers \& Vince 1997:17).

La importancia del estudio de esta tecnología radica en que, mediante diferentes líneas analíticas, es posible lograr un conocimiento sobre los individuos que produjeron los objetos alfareros y diversos aspectos de la sociedad en la que se gestaron, y así poner al desnudo la forma de actuar del hombre en relación con la naturaleza y con otros grupos humanos, las tradiciones en las cuales insertan, y su contexto sociocultural y económico (Arnold 2005:15; García Rosselló 2011:72).

Esto se debe a que la tecnología alfarera es el proceso y resultado de una "cadena operativa" (Leroi-Gourhan 1964), que depende y deriva de una serie de decisiones, conocimientos prácticas (conscientes o no) en cada una de las etapas de fabricación (selección, recolección y transporte de materias primas, preparación de pastas con arcillas y antiplásticos, elaboración de formas y diseño de decoraciones y cocciones), y que entrelaza destrezas de manufactura aprendidas y mantenidas mediante experiencias sociales y culturales que se desarrollan en un marco temporal y espacial específico (Balfet 1991; Lemonnier 1992). Todas las acciones y gestos técnicos expresados por los/as alfareros/as en la cadena operativa son plasmados y materializados en un estilo tecnológico cerámico, un conjunto de formas de hacer en el que los diferentes atributos alfareros son generalmente regulares y manifiestan (aunque no obligatoriamente de manera directa) identidad social o un proceso mediante el cual ésta es formada y transformada (Lechtman 1977; Sanhuesa 2006).

Entre las disciplinas que contribuyen a la comprensión de la producción cerámica del pasado se hallan aquellas derivadas de campo de las ciencias naturales, físicas y matemáticas. Esta línea de exámenes empleados para la resolución de problemas arqueológicos se la conoce como Arqueometría (Estévez Morales 1998:583). En alfarería, y particularmente en contextos en donde se carece de otro tipo de información histórica y/o antropológica, la aplicación de los métodos arqueométricos resulta muy útil. Normalmente son aprovechados para responder cuestiones referidas al uso de materias primas para la fabricación, comparando la química, mineralogía y petrografía de las pastas y pigmentos cerámicos con la geología de la región (arcillas, arenas y limos), así como también para indagar en las diferentes fases de fabricación y las condiciones de depositación de las piezas.

Muchos son los autores que mencionan y explican las diferentes técnicas analíticas para los estudios arqueométricos cerámicos (Neff 1992; Glascock 1992; Clop 2008; entre otros). Entre los exámenes químicos más comunes para se hallan el análisis de activación de neutrones, la fluorescencia de rayos $\mathrm{X}$, y el análisis microscópico de barrido electrónico. Para el reconocimiento de la composición, estado y fases mineralógicas se utilizan, entre otros, la microespectroscopia Raman y la difracción de rayos X. Finalmente, para la determinación litológica y mineralógica de cerámicas y sedimentos arenosos se utiliza ampliamente el examen microscópico de láminas delgadas.

La cantidad de técnicas analíticas puede llegar a ser numerosa, pero sea cual sea el método que se emplee, debe advertirse que las estrategias seguidas por los/as ceramistas han sido y son socioculturalmente construidas, aprendidas y transmitidas, y no siempre tienen una base tecnológica y funcionalista, 
por lo que el vínculo entre estos análisis y el accionar de los productores no es directo ni sencillo (Sillar \& Tite 2000:14-17; Arnold 2005:20; Albero Santacreu 2014:2-4).

En este trabajo se exponen los resultados de los primeros análisis exploratorios de difracción de rayos $X$ (DRX), fluorescencia de rayos $\mathrm{X}$ (FRX), microscopía petrográfica e índice de plasticidad sobre arenas, arcillas y cerámicas del sitio arqueológico Tambería de Guandacol, ubicado en la actual provincia de La Rioja (Argentina).

Se trata de un asentamiento importante para la comprensión de la vida de las sociedades que habitaron el área entre aproximadamente los 1200 y 1600 AD. (De la Fuente 1973; Callegari \& Gonaldi 2007-2008; Bárcena 2010). Si bien se ha avanzado en el estudio composicional y tecnológico de las alfarerías del sitio (Carosio, Iniesta \& Bárcena 2011; Carosio 2015, 2018; Carosio \& Iniesta 2017, entre otros), hasta el momento se desconoce el potencial y características de los recursos locales para su posible utilización en la manufactura por parte de los/as alfareros/ as que habitaron la zona en tiempos prehispánicos.

La problemática esencial que guía este trabajo radica en el conocimiento de las fuentes de materias primas de los alrededores del sitio y sus propiedades idóneas o no para la producción, en otras palabras, de las primeras etapas de la cadena operativa, y así también en los aspectos tecnológicos y la circulación de ceramios en el área durante este extenso periodo.

Si bien la ubicación de materiales para la manufactura no puede vincularse estrechamente a la localización de las actividades de producción, a través de investigaciones etnoarqueológicas se ha indicado que los/as ceramistas a menudo utilizan las materias primas disponibles localmente, esencialmente cuando la fabricación tiene un carácter doméstico (Arnold 1991:93), como se señalado para nuestra área de estudio (Carosio 2015).

En ese sentido, los estudios arqueométricos mencionados conforman una herramienta que aumenta la información hasta ahora reconocida, y posibilita un primer acercamiento a la composición de sedimentos y cerámicas (y su relación), así como el reconocimiento de algunos comportamientos tecnológicos de los materiales.

De esta forma, el objetivo principal de este trabajo es sentar las bases preliminares de información composicional y de propiedades tecnológicas sobre una muestra exploratoria para, a futuro, contribuir a la discusión sobre la problemática de la apropiación y potencialidad de materias primas de la región, y la manufactura alfarera desarrollada por las poblaciones que habitaron Guandacol durante los momentos prehispánicos.

\section{UBICACIÓN Y GEOLOGÍA DEL ÁREA DE ESTUDIO}

La Tambería de Guandacol se ubica en el valle andino homónimo, a los $1050 \mathrm{msnm}$, entre las Sierras Pampeanas y la Precordillera, en el oeste de la provincia de La Rioja, noroeste de Argentina, como muestra la figura 1a. Se trata de una depresión colmada principalmente de rellenos terciarios y cuaternarios, producto de la erosión dada por diversos agentes naturales. El clima del área es árido y seco, con lluvias estivales torrenciales, y vientos cálidos, lo que ha generado un ambiente semidesértico y vegetación xerófila (Tripaldi y Limarino 2008:48).

La geología del área exhibe series de diversas edades y composición (Furque 1963; Gentili 1972; entre otros). Hacia el oeste, la Precordillera está representada por numerosas series sedimentarias e ígneas (Formaciones Áspero, Cerro Morado, Volcán y El Corral, entre las principales) compuestas de calizas, lutitas, limonitas, areniscas, andesitas, riolitas, dacitas, granitos, granodioritas, etc.

El río Guandacol se forma aquí, y arrastrando junto a sus afluentes el material hasta el valle bajo, forma la cuenca con material fino/muy fino, generalmente bien seleccionado. Hacia el este, las Sierras Pampeanas 
Fuente: Elaboración propia en base al programa Google Mpas y Google Earth, y fotografías sobre los diferentes lugares de recolección de sedimentos efectuados en prospecciones arqueológicas.

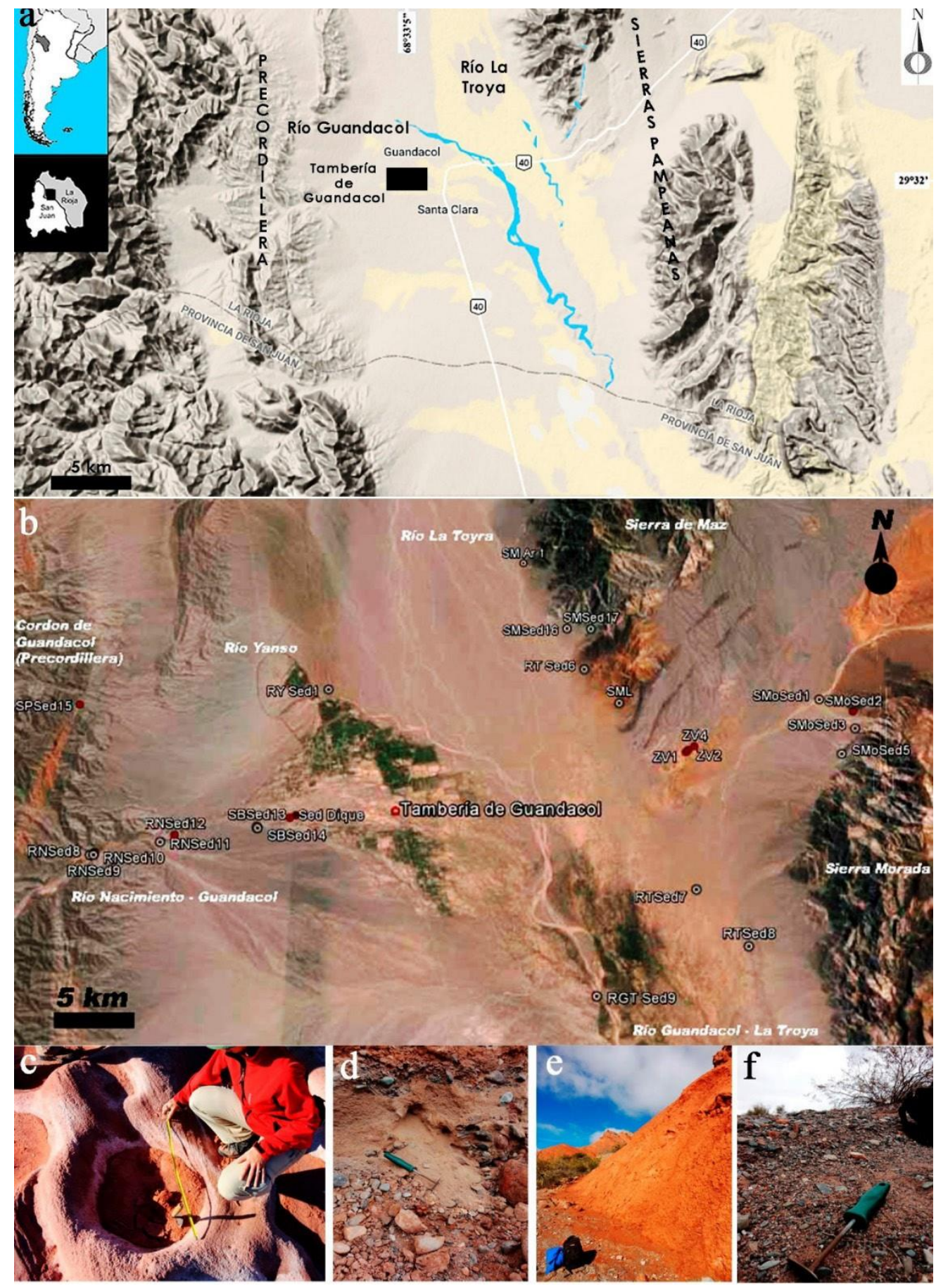

Figura 1: a) Ubicación del sitio Tambería de Guandacol en el marco regional. b) Mapa de distribución de sedimentos obtenidos para el estudio exploratorio (los círculos más oscuros representan arcillas, los más claros, arenas y limos). c) Muestra de arcilla ZV4. d) Muestra de arena RN Sed 10. e) Muestra de arcilla SP Sed 15. f) Muestra de arena SB Sed 13.

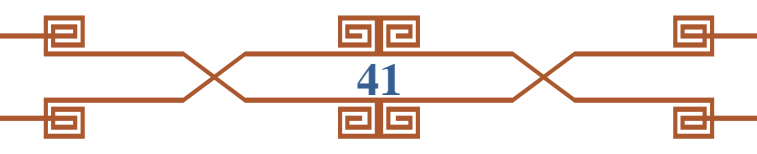


Sobre ellas se apoyan rocas sedimentarias y volcánicas alteradas de la Formación Aguas Blanquitas, y sedimentitas neopaleozoicas del Grupo Paganzo (formaciones Guandacol, Tupe y Patquía), areniscas, arcillitas, lutitas y conglomerados. Además se hallan arcillas del tipo clorita, montmorillonita, illita y caolinita.

Luego se encuentra la secuencia clástico/ volcánica de la triásica Formación Talampaya, con basaltos, areniscas y conglomerados, a la que suprayacen areniscas y conglomerados de la Formación Tarjados. Le sucede el Grupo Agua de la Peña (Formaciones Los Rastros, Ischigualasto y Los Colorados), y la cretácica Formación Cerro Rajado, integradas de pelitas, areniscas, basaltos y otros, que alternan con capas arcillosas/limosas. El Terciario se manifiesta por rodados metamórficos, sedimentarios y volcánicos. Finalmente, el Cuaternario se representa en los conos de deyección del rio Guandacol/La Troya, exhibiendo sedimentos con guijarros del material de arrastre serrano.

\section{ANTECEDENTES}

Si bien para la región del Noroeste Argentino existen numerosos estudios arqueométricos sobre cerámica arqueológica (Bertolino \& Fabra 2003; De la Fuente, Ratto, Toselli \& Plá 2008; Cremonte \& Botto 2009; Puente, Plá \& Invernizzi 2014; Páez \& Plá 2015; entre otros), para Guandacol y en general para la provincia de La Rioja hasta el momento no existen muchos antecedentes.

Los primeros trabajos regionales (Debenedetti 1917; Boman 1927-1932) describieron al conjunto de restos materiales (entre ellos la alfarería) predominante del actual oeste de Catamarca, La Rioja y el norte de San Juan (Argentina) como parte del complejo cultural denominado Sanagasta o Angualasto; el cual luego fue asignado al período Agroalfarero Tardío o de Desarrollos Regionales (ca. 1200-1470 AD), dentro de la secuencia cultural del Noroeste argentino (González \& Pérez 1972:37; Tarragó 2000).
La Tambería ha sido hasta el momento el sitio más estudiado en Guandacol (De la Fuente 1973; Callegari \& Gonaldi 2007-

2008; Bárcena 2010), sin embargo, también se hallan numerosos sitios en zonas cercanas, en el área de Santa Clara, San Bernardo, entre otros (Iniesta \& Bárcena 2014).

Las investigaciones iniciales en la Tambería relevaron y caracterizaron las estructuras arquitectónicas y cerámicas del sitio, y establecieron los primeros fechados, señalándolo como parte de la cultura Sanagasta/Angualasto durante el Tardío y el dominio Inca regional (aproximadamente entre los 1200 y 1600 AD). Nuestros trabajos incluyeron prospecciones, estudios arquitectónicos, relevamiento de nuevos sitios en el área, recolecciones superficiales de materiales, excavaciones, reconocimientos del arte rupestre, y fechados radiocarbónicos y de termoluminiscencia. En la Tambería se identificaron numerosas estructuras de barro, una zona incaica, recintos de almacenaje, canales de riego y campos de cultivo, instrumentos líticos, restos botánicos y de fauna; evidencias asignadas al mismo lapso que los trabajos previos (Bárcena 2010).

En cuanto a la alfarería, los primeros estudios mencionados establecieron la abundancia del estilo tecnológico Sanagasta/Angualasto, entre otros como el Inca Provincial, Diaguita Chileno Inca y Aguada. Esta último estilo es complejo y discutido cronológicamente en la región, dado que hasta el momento se ha asignado en Guandacol al periodo de Integración Regional o a una etapa que involucra a los Desarrollos Regionales (ca. 1200-1500 AD) (Iniesta \& Bárcena 2014:77), aunque su evidencia en áreas cercanas (La Rioja y norte de San Juan) registra cronologías anteriores y posteriores a las señaladas (Michieli 2007; Callegari \& Gonaldi 2006). También se amplió la caracterización y número del universo cerámico, su distribución espacial y su relación con el contexto arqueológico (Carosio et al. 2011), y se avanzó en la caracterización petrográfica de pastas cerámicas, estableciendo para la 
mayor parte de las piezas una composición correspondiente con la geología local (Carosio 2015, 2018; Carosio \& Iniesta 2017).

\section{METODOLOGÍA}

En este artículo de investigación, la muestra de sedimentos y de cerámica estudiada proviene de diversas prospecciones sistemáticas realizadas en el sitio y el área. En el caso de los sedimentos -arenas, limos y arcillas-, se trabajó con un total de 27 muestras. Cinco (5) de las muestras de arcillas son de Precordillera (S34 - Sed Dique - SP Sed 15 - RN Sed 10 - RN Sed 12 o cantera) y cuatro (4) de Sierras Pampeanas (ZV1 - ZV2 - ZV4 - SMo Sed 2), recuperadas a partir de la información de los pobladores locales y los estudios geológicos locales. Por suparte, las arenas/limos de Precordillera son seis (6) (RN Sed 8 - SB Sed 13 - RN Sed 11 - SB Sed 13 - SB Sed 14 - RY Sed 1), ocho (8) de Sierras Pampeanas (SMo Sed 1 - SMo Sed 3 - SMo Sed 5 - SM AR 1 - SM Sed 16 SM Sed 17 - SML - RT Sed 6), y finalmente tres (3) del cauce de los ríos Guandacol y La Troya (RGT Sed 7 - RGT Sed 7 - RGT Sed 9). Como exhibe la figura $1 b$, la recolección se efectuó esencialmente en las faldas occidentales de las sierras de Maz y Morada, en las orientales de la Precordillera, y sobre los márgenes de los ríos Guandacol y La Troya, no superando en ningún caso los 15 $\mathrm{km}$ a la redonda del sitio.

En el caso de las cerámicas se seleccionó una muestra exploratoria de nueve (9) tiestos de la Tambería, seis (6) de ellos correspondientes al estilo predominante del sitio Sanagasta/Angualasto, y los tres (3) restantes a otros estilos minoritarios, como se indica en la tabla 1.

Al ser una muestra netamente experimental, la elección arbitraria dentro del primer estilo respondió a la relativa variabilidad en la composición de pastas demostrada en estudios previos (Carosio 2015, 2018): abundantes inclusiones arcillosas, tiesto molido, rocas de diverso origen y gran cantidad de minerales félsicos y máficos (cuarzos, feldespatos, minerales opacos, biotita y muscovita).

Sin embargo, cuatro de ellos (TG 32b, TG T4 100, TG 264b, TG T5 423), poseen

importante carga de vulcanitas félsicas (vidrio volcánico alterado), además de que forman parte de vasijas que se intuyen como parte de un repertorio de piezas destinadas a la actividad culinaria. Esto les confiere una particularidad dentro del registro general. $\mathrm{La}$ selección del resto de los fragmentos respondió a una comparación con los restantes estilos del sitio.

El estilo Inca Provincial se compone de cuarzo, micas y abundantes litoclastos volcánicos y plutónicos. La alfarería Aguada, con muy baja densidad de antiplásticos y muy fino, posee cuarzo, feldespatos, micas, y escasas rocas volcánicas y sedimentarias. Finalmente, la Diaguita Chileno Inca se destaca por contener de los minerales recién mencionados, además de rocas volcánicas y plutónicas.

Los sedimentos se estudiaron inicialmente mediante observación macroscópica y submacroscópica, utilizando lupa binocular KYOWAOPTICAL SDZ-PL, en busca de la identificación (en los casos posibles) y caracterización de los constituyentes minerales y litológicos, incluyendo: color, aspecto, tamaño y desgaste. Además, se les adhirió ácido clorhídrico para establecer la presencia o ausencia de carbonato de calcio $\left(\mathrm{CaCO}_{3}\right)$ (Folk 1951:128-130; Compton 1962:282-289; Munsell Color 1994).

A las arcillas se le practicó un estudio geotécnico denominado Límites deAtterberg, el cual determina el intervalo de humedades en el que una masa arcillosa es moldeable, definiendo un índice de plasticidad (IP). El método sirve para reconocer su grado de plasticidad, su comportamiento tecnológico que se da en función de la relación agua/ arcilla, de las propiedades fisicoquímicas del material, y que depende de las condiciones en las que se aplique una fuerza deformadora (dirección y velocidad). 
De esta forma, es posible acercarse a sus propiedades de trabajabilidad (Ginés, Feliu, García-Ten \& Sanz 1997:27). Para su reconocimiento se realizó el tamizado de arcillas mediante tamiz $\mathrm{N}^{\circ} 40(425 \mu \mathrm{m}), \mathrm{y}$ luego, a través de un equipo estándar de Casagrande se procedió con el ensayo para determinar el IP. Los valores determinados fueron: el límite líquido, límite plástico e índice de plasticidad.

A las arenas en particular se le practicó un examen petrográfico con microscopio (OLYMPUS BX51), seleccionando seis láminas delgadas del total de muestras de acuerdo al tamaño de grano. Se contabilizaron 300 puntos por corte, describiendo tamaño, desgaste, selección, madurez textural y mineralógica (Raith, Raase \& Reinhardt 2012:30-110). Los resultados se compararon con los datos petrográficos de 111 láminas delgadas de pastas cerámicas obtenidos y publicados previamente (Carosio 2015, 2018; Carosio \& Iniesta 2017). Este examen aporta información de carácter cualitativo y cuantitativo de los componentes litológicos y mineralógicos, sin embargo la correspondencia geológica entre sedimentos y cerámicas no siempre es directa, y a diferencia de lo que sucede con los métodos químicos, son difíciles de aplicar en pastas demasiado finas o con un grado de cocción muy elevado, y en sedimentos arenosos de tamaño limo o arena muy fina (Stoltman 1989:158).

Todos las arcillas y cerámicas fueron analizados a través de estudios de difracción de rayos $\mathrm{X}$ (DRX), y fluorescencia de rayos $\mathrm{X}$ (FRX). La DRX es un método que permite identificar la mineralogía de la fracción arcillosa de estos materiales, así como de pigmentos y de minerales no plásticos. Además se utiliza para obtener información sobre las temperaturas de cocción a la que fueron sometidos los recipientes, en base a la transformación de algunas especies minerales en otras (Cremonte \& Bugliani 2006-2009:248).

Para este estudio se molieron las muestras a malla $200 \mu \mathrm{m}$ y se colocaron en portamuestras específicos, se utilizó un difractómetro de polvo Rigaku D-MAX III $\mathrm{C}$, con anticátodo de $\mathrm{Cu}(\lambda=1,5406 \AA) \mathrm{y}$ filtro de $\mathrm{Ni}$, bajo condiciones de $30 \mathrm{Kv}$ y 20 $\mathrm{mA}$, a una velocidad de barrido de $0,2^{\circ}-0,3^{\circ}$ $(2 \theta) / \mathrm{min}$ y a un paso de adquisición de datos de $2 \theta$ entre $0,02^{\circ}-0,05^{\circ}$. Los difractogramas fueron interpretados con el programa Match! Por su parte, para la FRX las muestras se molieron mediante mortero de ágata hasta malla $200 \mu$, y luego se montaron sobre pastillas de ácido bórico de $3,5 \mathrm{~g}$. Se requirieron $150 \mathrm{mg}$ por muestra, las cuales fueron compactadas a $10 \mathrm{~kb}$. Se utilizó un espectrómetro dispersivo en longitud de onda (WDS) Philips - PW 1400.

Los datos obtenidos fueron comparados con patrones de referencia internacional USGS (U. S. Geological Survey) y ANRT (Association National of the Research Technique); y para la interpretación de los perfiles composicionales se realizó un procesamiento de datos bajo el paquete estadístico GCDKIT 4.1. La FRX es una de las técnicas que permiten reconocer la composición química elemental de alfarerías y sedimentos, posibilitando relaciones entre ellos para acercarse a las fuentes de materias primas, aunque la obtención de resultados óptimos dependerá de una buena localización de los materiales en el área de estudio, el número de muestras a analizar, los tratamientos técnicos sobre las materias primas con las que se conformaron las pastas cerámicas y las condiciones en que se depositaron los materiales una vez que dejaron de utilizarse y formaron parte del registro arqueológico (Cremonte \& Bugliani 2006-2009:251). 
Tabla 1: Características de fragmentos cerámicos analizados.

\begin{tabular}{|c|c|c|c|c|}
\hline TIESTO & $\begin{array}{l}\text { COLOR } \\
\text { DE PASTA }\end{array}$ & $\begin{array}{c}\text { PARTE DE } \\
\text { RECIPIENTE - }\end{array}$ & $\begin{array}{c}\text { ESTILO } \\
\text { TECNOLÓGICO } \\
\text { CERÁMICO } \\
\end{array}$ & $\begin{array}{l}\text { PERIODIZACIÓN } \\
\text { REGIONAL }\end{array}$ \\
\hline TG 198b & $\begin{array}{c}\text { marrón } \\
\text { rojizo } \\
(2.5 \mathrm{YR} 4 / 6)\end{array}$ & $\begin{array}{l}\text { cuerpo - plato/ } \\
\text { cuenco }\end{array}$ & Diaguita Chileno Inca & $\begin{array}{l}\text { Dominación Inca (ca. } \\
\quad 480 \text { - } 415 \text { AP) }\end{array}$ \\
\hline TG 220b & $\begin{array}{c}\text { naranja } \\
(10 \mathrm{YR} 6 / 8)\end{array}$ & cuerpo - cuenco & Aguada & $\begin{array}{c}\text { Integración Regional/ } \\
\text { Desarrollos } \\
\text { Regionales (ca. } 800 \text { - } \\
500 \text { AP) }\end{array}$ \\
\hline TG $314 b$ & $\begin{array}{c}\text { rojizo } \\
(2.5 \mathrm{YR} 4 / 8)\end{array}$ & $\begin{array}{l}\text { cuerpo - aríbalo/ } \\
\text { aribaloide }\end{array}$ & Inca Provincial & $\begin{array}{c}\text { Dominación Inca (ca. } \\
480 \text { - } 415 \text { AP) }\end{array}$ \\
\hline TG 264b & $\begin{array}{l}\text { marrón } \\
\text { grisáceo } \\
\text { (10YR 6/2) }\end{array}$ & cuerpo - olla & Sanagasta/Angualasto & $\begin{array}{c}\text { Desarrollos } \\
\text { Regionales (ca. } 700 \text { - } \\
480 \mathrm{AP})\end{array}$ \\
\hline TG T5 408 & $\begin{array}{c}\text { naranja } \\
\text { rojizo } \\
\text { (7.5YR 5/8) }\end{array}$ & cuerpo - olla & Sanagasta/Angualasto & $\begin{array}{c}\text { Desarrollos } \\
\text { Regionales (ca. } 700 \text { - } \\
480 \text { AP) }\end{array}$ \\
\hline TG T5 3 & $\begin{array}{c}\text { rojizo } \\
(2.5 \mathrm{YR} 4 / 8)\end{array}$ & cuerpo - cuenco & Sanagasta/Angualasto & $\begin{array}{c}\text { Desarrollos } \\
\text { Regionales (ca. } 700 \text { - } \\
480 \text { AP) }\end{array}$ \\
\hline TG T5 92 & $\begin{array}{c}\text { rojizo } \\
(2.5 \mathrm{YR} 4 / 8)\end{array}$ & cuerpo - cuenco & Sanagasta/Angualasto & $\begin{array}{c}\text { Desarrollos } \\
\text { Regionales (ca. } 700 \text { - } \\
480 \text { AP) }\end{array}$ \\
\hline TG T4 100 & $\begin{array}{l}\text { marrón } \\
\text { grisáceo } \\
(10 Y R \text { 6/2) }\end{array}$ & cuerpo - olla & Sanagasta/Angualasto & $\begin{array}{c}\text { Desarrollos } \\
\text { Regionales (ca. } 700 \text { - } \\
480 \text { AP) }\end{array}$ \\
\hline TG T5 188 & $\begin{array}{c}\text { naranja } \\
\text { rojizo } \\
\text { (7.5YR 5/8) }\end{array}$ & cuerpo - cuenco & Sanagasta/Angualasto & $\begin{array}{c}\text { Desarrollos } \\
\text { Regionales (ca. } 700 \text { - } \\
480 \text { AP) }\end{array}$ \\
\hline
\end{tabular}

Fuente: Elaboración propia en base a la observación con lupa binocular (KYOWAOPTICAL SDZ-PL) de fragmentos.

\section{RESULTADOS Y DISCUSIÓN}

ANÁLISIS

SUBMACROSCÓPICOS

Y GEOTÉCNICOS DE SEDIMENTITAS ARCILLOSAS
Las muestras son primarias, de depósitos de origen, y secundarias, meteorizadas y transportadas por agentes naturales. La tonalidad general de los sedimentos es marrón rojizo (5YR 4/6) y marrón (7.5YR $5 / 3$ ). Como se advierte en la figura 2 , se reconocen impuras y magras, de aspecto laminar/granular, con bajo contenido orgánico, y con minerales como cuarzo, feldespato y rocas (pelitas, arcillitas yotras de difícil interpretación). Poseen en 
general un desgaste redondeado y subredondeado, por lo que ostentan selección buena y una madurez textural madura. Asimismo, se observan con baja reacción al ácido clorhídrico, por lo que no tienen alto contenido de material calcáreo.

En relación con el índice de plasticidad, no todas las arcillas poseen (SP); solamente tres exhiben algo de plasticidad: la proveniente de Precordillera (Sed Dique) posee un IP de 0,49, y las dos muestras recuperadas del área de Sierras Pampeanas (ZV1 y SMoSed 2) tienen un IP de 6,75 y 2,7 respectivamente.
El contraste en algunos datos es muy grande, si bien existen muestras con un límite líquido alto, 31,5 (como SP SED 15), no poseen límite plástico. Tal como muestra la tabla 2, en general la variación de resultados del límite líquido es algo mayor que los del límite plástico. Las arcillas de Sierras Pampeanas son del tipo CL o arcilla de baja plasticidad, y las de Precordillera, también con IP muy bajo, son suelos del tipo ML o limo/arenas de baja plasticidad, según la Clasificación Unificada de Suelos (S.U.C.S.).

Fuente: Elaboración propia en base a la observación con lupa binocular (KYOWAOPTICAL SDZ-PL) de sedimentos.
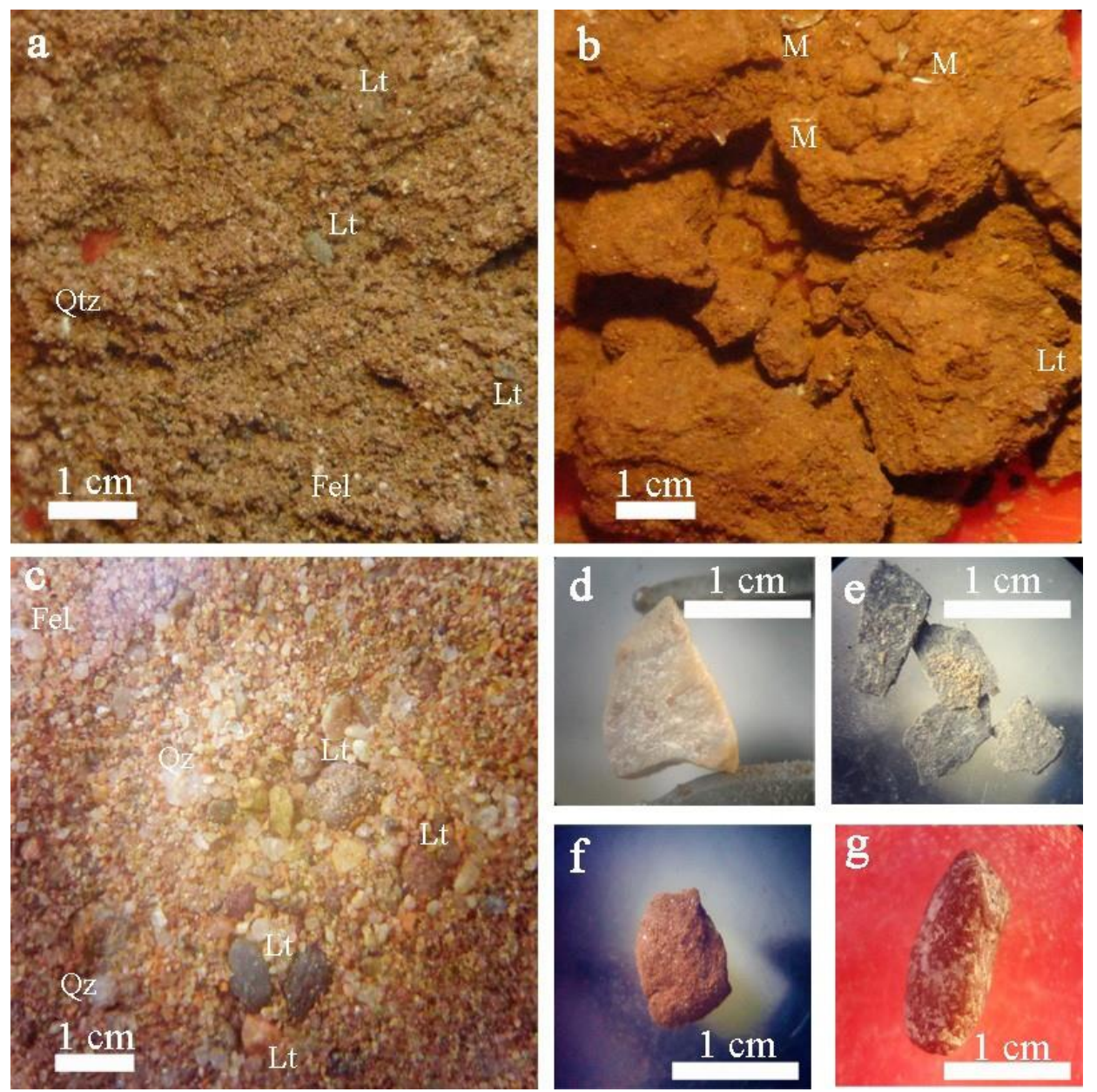

Figura 2: Fotografías, mediante lupa binocular, de sedimentos arcillosos y arenosos.

Referencias: Lt (lítico), Qtz (cuarzo), Fel (feldespato), M (mica). a) RN Sed10. b) SP Sed15.

c) RGT Sed7. d) Feldespato potásico (RGT Sed7). e) Filitas (SM Sed 16). f) Arenisca (RN Sed8). g) Riolita (RN Sed8).

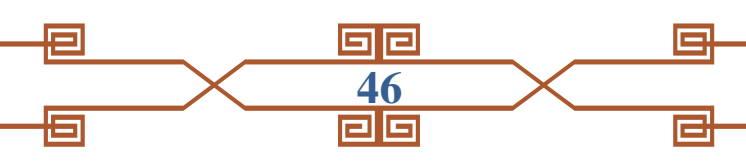


Tabla 2: Resultados de análisis de Límites de Atterberg de muestras arcillosas.

\begin{tabular}{|c|c|c|c|}
\hline Arcilla & Límite Líquido & Límite Plástico & IP \\
\hline RN Sed 10 & 19,2 & SP & 9,1 \\
\hline $\begin{array}{c}\text { RN Sed 12 } \\
\text { (cantera) }\end{array}$ & 25,1 & SP & SP \\
\hline S 34 & 24,1 & SP & 4,5 \\
\hline Sed Dique & 29 & 28,51 & 0,49 \\
\hline SMo Sed 2 & 24,3 & 21,6 & 2,7 \\
\hline SP Sed 15 & 35,5 & SP & SP \\
\hline ZV1 & 28 & 21,25 & 6,75 \\
\hline ZV2 & 20,1 & SP & SP \\
\hline ZV4 & 19,8 & SP & SP \\
\hline
\end{tabular}

Fuente: Elaboración propia en base los datos obtenidos a través del uso del equipo estándar de Casagrande.

\section{ANÁLISIS SUBMACROSCÓPICOS Y MICROSCÓPICOS DE ARENAS}

Las arenas tienen una madurez mineralógica madura, es decir, se trata de sedimentos con importante carga de cristales de cuarzo y feldespato, además de micas y rocas, como indica la tabla 3. En la figura 3 se puede observar la distinción de diferentes especies minerales y rocas, como biotita, muscovita, óxidos $\mathrm{Fe}$, anfíboles, piroxenos, minerales opacos, y litoclastos ígneos, sedimentarios y metamórficos. El cuarzo posee extinción recta y forma anhedral, los feldespatos forma subhedral, maclas y clivaje, y en ocasiones alteración (a sericita y arcillas). La muscovita $\mathrm{y}$ biotita exhiben forma foliada $\mathrm{y}$ alta birrefringencia.

En cuanto a las rocas, las volcánicas máficas (basaltos) se reconocen por su textura porfidítica, las félsicas (riolitas) e intermedias (andesitas y dacitas) por su textura afanítica. Las plutónicas (granitos), tienen textura fanerítica. Los litoclastos sedimentarios tienen origen fundamentalmente detrítico (areniscas, lutitas, limolitas y pelitas), y los metamórficos (esquistos, pizarras, filitas) exhiben texturas granoblástica y lepidogranoblástica.
Estos constituyentes de arenas poseen tamaños entre 0,05 y $4 \mathrm{~mm}$, y formas predominantemente sub-redondeadas y esféricas o sub-prismáticas. La selección es pobre y equilibrada, y la madurez textural submadura. Se tratan de sedimentos transportados por cursos de agua desde el frente montañoso de diferentes formaciones geológicas del oeste, el norte y noreste del valle hasta el sitio de su depositación en la cuenca baja.

La particularidad del conjunto radica en que las rocas metamórficas se observan únicamente en las muestras del área baja y en las de Sierras Pampeanas, y en bajo porcentaje en una cercana a la Tambería (SBSed 13), muy probablemente como producto del relleno de formación del barreal. Otro detalle es que la reacción al ácido clorhídrico es nula/baja en las de Sierras Pampeanas, y baja/moderada en las de Precordillera, denotando que éstas son levemente más calcáreas. 
Tabla 3: Análisis modal de los sedimentos arenosos estudiados por petrografía. Valores se expresan en porcentajes. Qz (cuarzo), Fk (feldespato potásico), Plag (plagioclasa), Mi (microclino), Bt (biotita), Ms (muscovita), Anf (anfibol), Px (piroxeno), Cal (calcita), Mo (opaco), Lvm (litoclasto volcánico máfico), Lvi (litoclasto volcánico intermedio), Lvf (litocasto volcánico félsico), Lp (litocasto pultónico), Lm (litoclasto metamórfico), Ls (litoclasto sedimentario)

\begin{tabular}{|ccccccc|}
\hline \multicolumn{7}{c|}{ ARENAS } \\
\hline Composición & RGTSed7 & SMoSed1 & RNSed8 & SBSed13 & RGTSed9 & SMSed16 \\
\hline Qz & 20,16 & 31,66 & 19,16 & 20 & 21,33 & 32,16 \\
\hline Fk & 8,16 & 7,33 & 15,5 & 1,16 & 10 & 4,83 \\
\hline Plag & 6,16 & 0,16 & 13,16 & 0,16 & 7,83 & - \\
\hline Mi & 0,33 & - & - & 0,16 & - & - \\
\hline Bt & 2,83 & 1,33 & 1,16 & 3,16 & 3,16 & 7,16 \\
\hline Ms & 5,33 & 2,66 & 3,86 & 5 & 7,66 & 5,16 \\
\hline Anf & 0,16 & 0,16 & - & - & 0,16 & 0,16 \\
\hline Px & - & 0,83 & 0,16 & - & 0,66 & 5,85 \\
\hline Cal & 1,5 & - & 1,33 & 2,33 & 1,83 & - \\
\hline Mo & 5,83 & 7,33 & 5,16 & 7,83 & 5 & 4,16 \\
\hline Lvm & 17 & 1,33 & 7,16 & 15,16 & 1,33 & 1 \\
\hline Lvi & 0,33 & - & - & 1,16 & 0,33 & - \\
\hline Lvf & 2,33 & 8,66 & - & 21,16 & 3,33 & 1,33 \\
\hline Lp & 0,5 & - & 3,16 & 0,33 & 0,16 & - \\
\hline Lm & 13 & 16,26 & - & 1,16 & 17 & 13 \\
\hline Ls & 16,33 & 22,26 & 30,16 & 21,16 & 20,16 & 25,16 \\
\hline TOTAL & 99,95 & 99,97 & 99,97 & 99,94 & 99,94 & 99,97 \\
\hline Funte
\end{tabular}

Fuente: Elaboración propia a partir de conteo de 300 puntos por lámina delgada 
Fuente: Elaboración propia a partir de fotografías realizadas en microscopio OLYMPUS BX51.

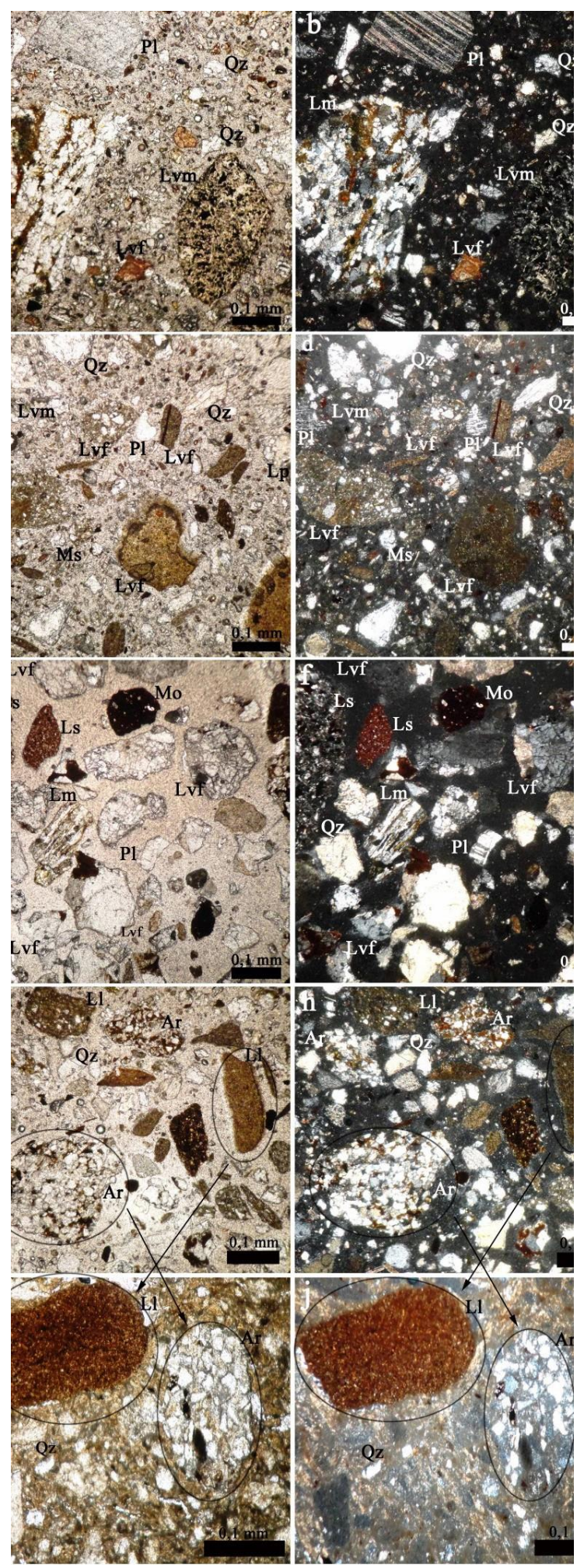

Figura 3: Microfotografías de arenas y cerámica Sanagasta/Angualasto (izquierda: sin polarizador - derecha: con polarizador). Referencia: Lvf (lítico volcánico félsico), Lvm (lítico volcánico máfico), Lm (lítico metamórfico), Ls (lítico sedimentario), Lp (lítico plutónico),

Qz (cuarzo), Pl (plagioclasa), Ar (arenisca - lítico sedimentario), Ll (limolita - lítico sedimentario) y Ms (muscovita). a y b) RGT Sed7. c y d) RN Sed8. e y f) SMo Sed1. g y h) RGT Sed9. i y j) Fragmento cerámico del estilo Sanagasta/Angualasto (Carosio 2015). 
Al comparar estos datos con los resultados petrográficos cerámicos obtenidos previamente (Carosio 2015, 2018), se advierte un vínculo composicional entre sí, particularmente con las pastas del estilo Sanagasta/Angualasto. Estas poseen no solo la misma mineralogía y litología sino también las mismas características de tamaño, selección, redondez y esfericidad. La alfarería Inca Provincial exhibe poca similitud, manifestada en la presencia de algunos litoclastos (andesitas, riolitas), cuarzos, feldespatos y micas. Las piezas Aguada normalmente poseen poca densidad de inclusiones antiplásticas, y entre éstas, advertimos semejanza en ciertas rocas volcánicas (riolitas), sedimentarias (areniscas) y metamórficas (filitas y/o pizarras).

Finalmente las cerámicas Diaguita Chileno Inca, si bien poseen minerales y algunos litoclastos del mismo origen que los de las arenas (andesitas, granitos y areniscas), varían por la ausencia de rocas metamórficas y otras volcánicas (riolitas, basaltos) y sedimentarias (lutitas, limolitas). Por otro lado, el desgaste y tamaño observado en las arenas es similar a las de las pastas de los conjuntos locales, esencialmente con las piezas Sanagasta/Angualasto, tal como exhibe la figura $3 \mathrm{~g}, \mathrm{~h}, \mathrm{i}, \mathrm{j}$.

\section{ANÁLISIS DE DIFRACCIÓN DE RAYOS X DE ARCILLASY CERÁMICAS}

Mediante DRX se determinó que arcillas y cerámicas se presentan ricas en minerales arcillosos como illita $\left(\mathrm{KA}_{12} \mathrm{O}_{3 \cdot 4} \mathrm{SiO}_{2} \cdot \mathrm{H}_{2} \mathrm{O}\right)$, seguido de esmectitas, probablemente montmorillonita, $\left(\mathrm{Si}_{4} \mathrm{O}_{10}\left(\mathrm{Al}_{2}-\mathrm{XR}_{2}+\mathrm{X}\right)(\mathrm{OH})_{2}\right.$ $\left.\mathrm{nH}_{2} \mathrm{Oc} . \mathrm{Xc}\right)$, y caolinita $\left(\mathrm{Al}_{2} \quad \mathrm{Si}_{2} \mathrm{O}_{5}(\mathrm{OH})_{4}\right)$, entre otros minerales no arcillosos como cuarzo $\left(\mathrm{SiO}_{2}\right)$. En las arcillas, la presencia de illita se identifica por sus reflexiones a 2 theta a $\operatorname{los} 9^{\circ}$, y la interestraficación illita/ esmectita a los 2 theta a $\operatorname{los} 11^{\circ}, 13^{\circ}$ y $16^{\circ}$.

Por su parte, la caolinita se reconoce a los 2 theta a $\operatorname{los} 12^{\circ}$ y $24^{\circ}$. Como muestra la figura 4 , el cuarzo se observa a 2 theta a $\operatorname{los} 26^{\circ}$, y los restantes picos de las diferentes series se encuentran levemente desplazados de las reflexiones racionales, reconociendo así la presencia de mezclas de minerales arcillosos y no arcillosos.

La variación en las proporciones de minerales puede deberse a diferentes grados de meteorización de la roca en el lugar de muestreo, además de las variaciones composicionales que la misma pueda presentar. En líneas generales, entre las arcillas no hemos podido encontrar fuertes diferencias entre las muestras, salvo la presencia de esmectita exclusivamente en algunas sedimentitas de Sierras Pampeanas -ZV2 y ZV4-.

En cuanto a las cerámicas, la illita se identifica en los todos los tiestos por sus reflexiones a $\operatorname{los} 2$ theta a $\operatorname{los} 9^{\circ}$ y $28^{\circ}$, y la interestratificación illita/esmectita a los 2 theta a $\operatorname{los} 16^{\circ}$, aunque exclusivamente en los tiestos Sanagasta/Angualasto TG T4 100 y TG 264b. La caolinita se halla presente en casi todas las muestras, excepto en el fragmento Aguada -TG220b- y un fragmento Sanagasta/Angualasto -TG T5 92-, se exhibe a los 2 theta a los $24^{\circ}$. El cuarzo se exhibe a $\operatorname{los} 2$ theta a $\operatorname{los} 26^{\circ}$, como indica la figura 5 . 
Fuente: Elaboración propia a partir del programa Match!

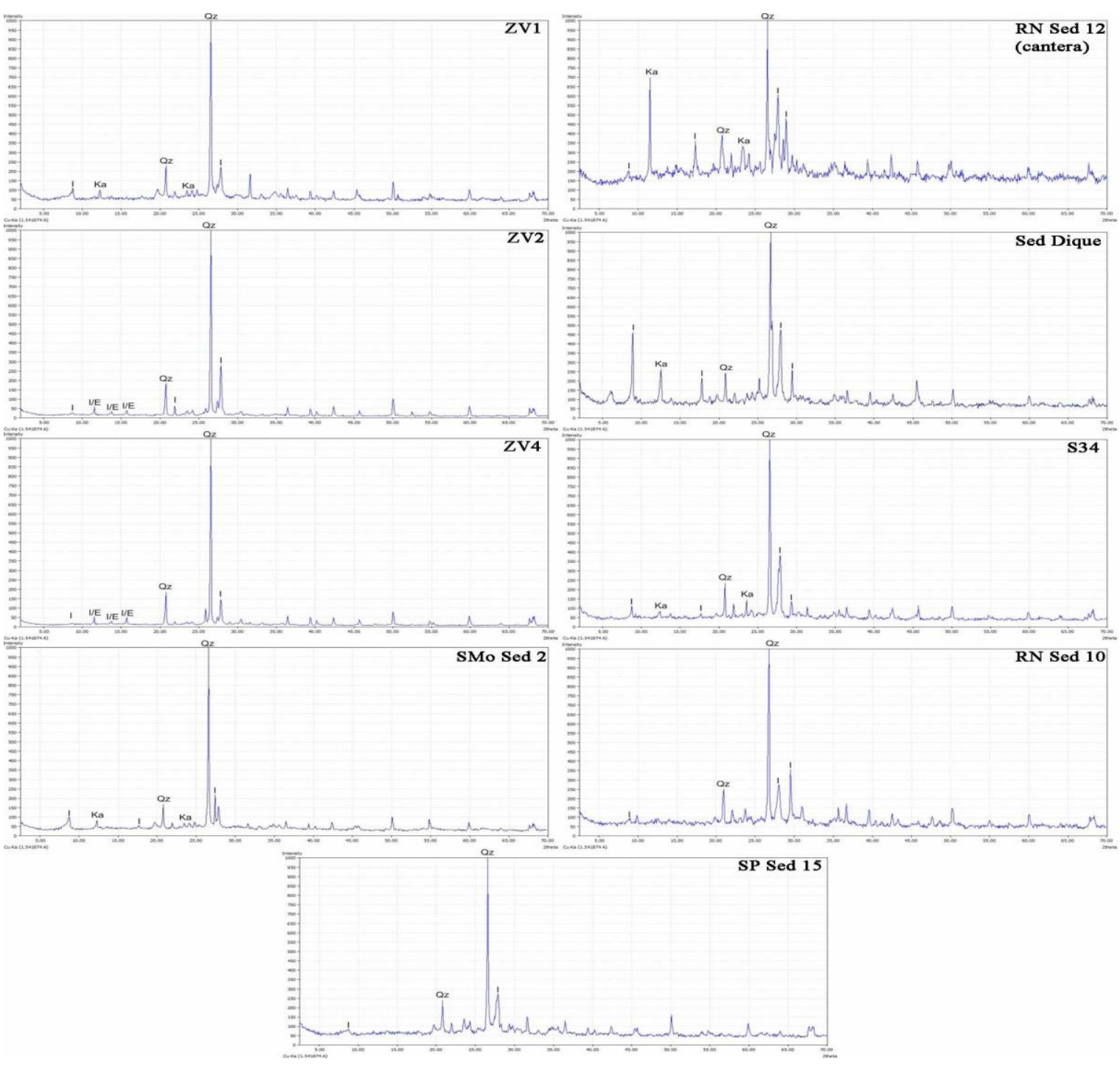

Figura 4: Difractogramas de arcillas. Referencias: I (illita), Ka (caolinita), Qz (cuarzo), I/E (illita/esmectita). 
Fuente: Elaboración propia a partir del programa Match!

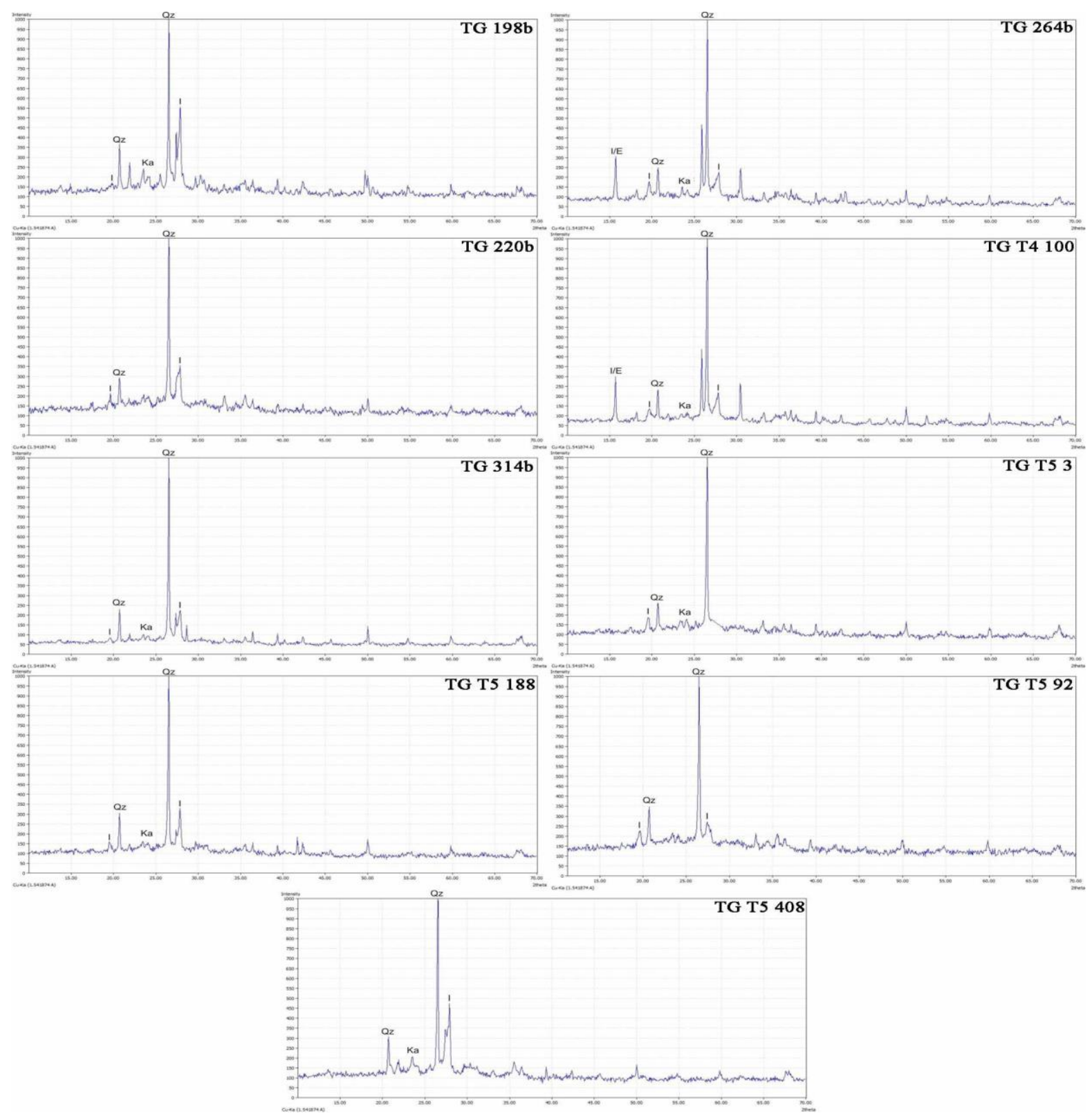

Figura 5: Difractogramas de cerámicas. Referencias: I (illita), ka (caolinita), Qz (cuarzo), I/E (illita/esmectita).

\section{ANÁLISIS DE FLUORESCENCIA DE RAYOS X DE ARCILLAS Y CERÁMICAS}

Mediante FRX se determinó para las pastas y los sedimentos arcillosos elementos mayoritarios ( $\mathrm{SiO}, \mathrm{Al} \mathrm{O}, \mathrm{Fe} \mathrm{O}, \mathrm{P} \mathrm{O}, \mathrm{K} \mathrm{O}$,

$\mathrm{CaO}, \mathrm{MgO}_{\text {y TiO}} 2$ ) y minoritarios $(\mathrm{Zn}, \mathrm{Cu}, \mathrm{Cr}$, $\mathrm{Ni}, \mathrm{Co}, \mathrm{Pb}, \mathrm{Zr}$ y Ba), tal como se observa en la tabla 4. Se exhibe una cierta homogeneidad composicional del registro global, aunque con ligeras diferencias en los porcentajes de cada óxido. El componente mayoritario es el $\mathrm{SiO}_{2}$, con valores aproximados entre el $75 \%$ y el $54 \%$ (media $=64,25 \%$ ). Le sigue el $\mathrm{Al}_{2} \mathrm{O}_{3}$, con valores que varían entre un $20 \%$ y un $15 \%($ media $=15,98 \%)$.

Estos valores en algunas de las muestras arcillosas corroborarían la presencia de

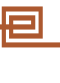


esmectita (probablemente montmorillonita) (Mas Pérez 1985:116-125). Luego continúa el $\mathrm{K}_{2} \mathrm{O}$ (media=9,75\%), lo que avalaría la presencia de illita, dado que estas normalmente poseen un mínimo de $6 \%$ - 7\% (Singer \& Singer 1971:38). Y ya con contenidos más bajos el $\mathrm{Fe}_{2} \mathrm{O}_{3}($ media=5,2\%) (el que otorga la tonalidad rojiza/marrón), el $\mathrm{CaO}($ media $=3 \%$ ) y el $\mathrm{MgO}$ (media=1\%). Con valor inferior al $0.5 \%$ aparecen otros óxidos.

En el caso específico de las arcillas se observó que las de Sierras Pampeanas se componen de mayor cantidad de $\mathrm{K}_{2} \mathrm{O}$ (probablemente reflejado en el filosilicato illita), mientras que las de Precordillera muestran mayores proporciones de $\mathrm{Al}_{2} \mathrm{O}_{3}$, representado probablemente en el filosilicato caolinita. Asimismo se advirtió que éstas son levemente más calcáreas y magnesianas frente a las de Sierras Pampeanas, ricas en zirconio y titanio, elementos importantes de las rocas ígneas, metamórficas, y sedimentos refractarios. Para el resto de los elementos químicos no se observa una tendencia discriminatoria abrupta.

En cuanto a los tiestos cerámicos, el estilo Sanagasta/Angualasto se caracteriza en general por poseer, entre los elementos minoritarios discriminadores, mayores cantidades de $\mathrm{Zr}, \mathrm{Pb}, \mathrm{Zn}, \mathrm{K}_{2} \mathrm{O}$ y $\mathrm{P}_{2} \mathrm{O}_{5}, \mathrm{y}$ menor cantidad de $\mathrm{Fe}_{2} \mathrm{O}_{3}$ que el resto de los estilos. Dentro de ese grupo con más cantidad de muestras, observamos que los existen un subgrupo compuesto por los tiestos TG T4 100 y TG 264b que exhiben mayoría de $\mathrm{Pb}, \mathrm{Zn}, \mathrm{Zr}$, y menor proporción de $\mathrm{Ba}, \mathrm{Ni}, \mathrm{TiO}_{2}$ y $\mathrm{Co}$ que el resto entre los elementos minoritarios.

Asimismo, exponen menos cantidad de $\mathrm{MgO}, \mathrm{Fe}_{2} \mathrm{O}_{3}$ y más $\mathrm{SiO}_{2}$. En general el estilo se asemeja a la pieza Inca Provincial y relativamente al tiesto Aguada, aunque éste presenta más contenido de $\mathrm{CaO}$ que el resto. Por su parte, el tiesto Diaguita Chileno Inca se separa ampliamente del resto de la muestra al contener abundante $\mathrm{Cu}$.

Al vincular las arcillas y los fragmentos, en base a los elementos mayoritarios y minoritarios con mayor significancia dentro de cada estilo cerámico, se lograron diferentes combinaciones tendientes a la discriminación y agrupación de muestras. Una de las combinaciones exploradas fue $\mathrm{TiO}_{2}-\mathrm{CaO}-\mathrm{K}_{2} \mathrm{O}$, a raíz de que el $\mathrm{TiO}_{2}$ y el $\mathrm{CaO}$ son elementos importantes para las sedimentitas de Sierras Pampeanas y Precordillera, respectivamente, y que $\mathrm{K}_{2} \mathrm{O}$

Tabla 4: Valores de elementos químicos de las muestras de arcillas y cerámicas analizadas mediante FRX.

\begin{tabular}{|c|c|c|c|c|c|c|c|c|c|c|c|c|c|c|c|c|}
\hline Muest & $\mathrm{Zr}$ & $\mathbf{P b}$ & Co & $\mathrm{Ni}$ & $\mathrm{Cu}$ & $\mathrm{Zn}$ & $\mathrm{Cr}$ & Ba & TiO2 & $\mathrm{CaO}$ & K2O & MgO & Al2O3 & $\mathrm{SiO} 2$ & P2O5 & $\mathrm{Fe} 2 \mathrm{O3}$ \\
\hline & & 0,0007 & & & & & & & & & 14,6501 & 1,2002 & 12,7005 & 62,6302 & 0,1502 & 6,9708 \\
\hline ZV2 & 5337 & 01 & & & & & & & & & 1,3902 & 0,5803 & 7001 & 73,4 & 1111 & 3,6009 \\
\hline $\mathbf{Z V}$ & 407 & 009 & & 023 & & & 0008 & 257 & & 7703 & & 7601 & 002 & 4,8001 & 001 & 2,75 \\
\hline S34 & & & & & & & & & & & 3,4002 & 0,9801 & 10,8003 & 60,7003 & 0,21 & 6,3607 \\
\hline Sed Dique & 0,034 & 0,0005 & 0,0013 & 0,0017 & 0,0014 & 0,0159 & 0,0039 & 0,0472 & 0,8301 & 4,9001 & 14,4203 & 1,2903 & 12,4004 & 59,3 & 0,1803 & 5,6008 \\
\hline SP SED 15 & 0,0095 & & & 0,0038 & & & 0,0043 & 7701 & & & & 8953 & 15,0951 & 71,2482 & & 4,2877 \\
\hline SMO SED 2 & 0,0131 & 0,0139 & 003 & 0,0047 & 0,0015 & 0,0 & 0,0054 & 0,0418 & 0,7 & 0,5345 & 12,8327 & 0,9659 & 20,5982 & 58,8969 & 0,0889 & 5,1759 \\
\hline RN SED 10 & 0,0073 & 0 & & 0 & & & & & & & & 1298 & 522 & & 737 & 2831 \\
\hline RN SED 12 & 0,0039 & 0,0001 & 0,0036 & 0,0073 & & 0,0036 & 0,0038 & 0,1558 & 0,355 & 4,6352 & 13,9 & 1,65 & 14,6591 & 54,2251 & & 9,9921 \\
\hline TG $220 \mathrm{~B}$ & 0,0087 & 0,0002 & 0,0031 & & & & & & & & & & & & & 6,4818 \\
\hline TG T5 92 & 0,014 & 0,0012 & 0,003 & 0,0054 & 0,0013 & 0,0044 & 0,0058 & 0,0854 & 0,7838 & 1,6907 & 12,9023 & 1,2214 & 19,3038 & 57,0002 & 0,2703 & 6,4195 \\
\hline TG T5 3 & 0,0145 & 0,0093 & ,003 & & 0,0014 & 0,0054 & 0,0058 & 0,1019 & & 1,6966 & 0,037 & 1,3432 & 20,5635 & 58,9009 & 219 & 5,9364 \\
\hline TG T4 100 & 0,0015 & 0,0292 & 0,0025 & 0,0033 & 0,0037 & 0,0083 & 0,003 & 0,0538 & 0,5304 & 1,215 & 2,218 & 0,6717 & 17,19551 & 74,3082 & 0,215 & 2,6473 \\
\hline TG T3 408 & 0,0175 & 0,0174 & 0,0029 & 0,0043 & & 0,0063 & & 0,0826 & 0,6433 & 2,7486 & 4,148 & 0,8449 & 19,376 & 66,4035 & 0,2672 & 4,4507 \\
\hline TG 264B & 0,2396 & 0,0369 & 0,0025 & 0,0032 & 0,0038 & 0,0082 & 0,0023 & 0,0408 & 0,3468 & 1,2578 & 4,2911 & 0,6028 & 19,2411 & 69,5579 & 0,2803 & 3,4145 \\
\hline TG 198B & 0,0168 & 0,0003 & 0,0031 & 0,0053 & 0,0323 & 0,0015 & 0,0029 & 0,0743 & 0,7827 & 2,0747 & 8,0501 & 1,0146 & 20,101 & 59,0001 & 1,0002 & 7,6445 \\
\hline TG 314B & 0,0192 & 0,0077 & 0,0027 & 0,0044 & 0,0018 & 0,0052 & & 0,0768 & & 1,2832 & 3,4623 & 0,9323 & 18,5773 & 68,7556 & 0,2918 & 5,3205 \\
\hline TG T5 188 & 0,0245 & 0,0004 & 0,003 & 0,0051 & 0,0001 & 0,0034 & 0,0056 & 0,0762 & 0,763 & 2,8096 & 5,896 & 1,0768 & 20,7423 & 61,2991 & 0,2041 & 6,4199 \\
\hline
\end{tabular}

Fuente: Elaboración propia a partir de los datos generados por el equipo Philips - PW 1400. 
es uno de los primordiales en la illita.

Como muestra la figura 6a, allí se pudo ver un vínculo entre prácticamente todos las cerámicas y las arcillas de Precordillera, y por otro lado, una discriminación de las del entorno de Sierras Pampeanas, excepto la muestra SMo Sed2. Sin embargo, al triangular el CaO-MgO- $\mathrm{P}_{2} \mathrm{O}_{5}$, elementos que marcaron las diferencias sustanciales entre las sedimentitas arcillosas, se advirtió la relación estrecha de algunas muestras de Sierras Pampeanas (ZV2 y parcialmente ZV4) con los tiestos del estilo Sanagasta/ Angualasto TG T4 100 y TG 264b, muestras en las que se reconoció exclusivamente esmectita. Asimismo se reconoció una correspondencia entre las piezas Inca Provincial y Aguada con algunas arcillas de Precordillera y tiestos Sanagasta/Angualasto, tal como se observa en la figura $6 b$.

Fuente: Elaboración propia a partir del programa GCDKIT.

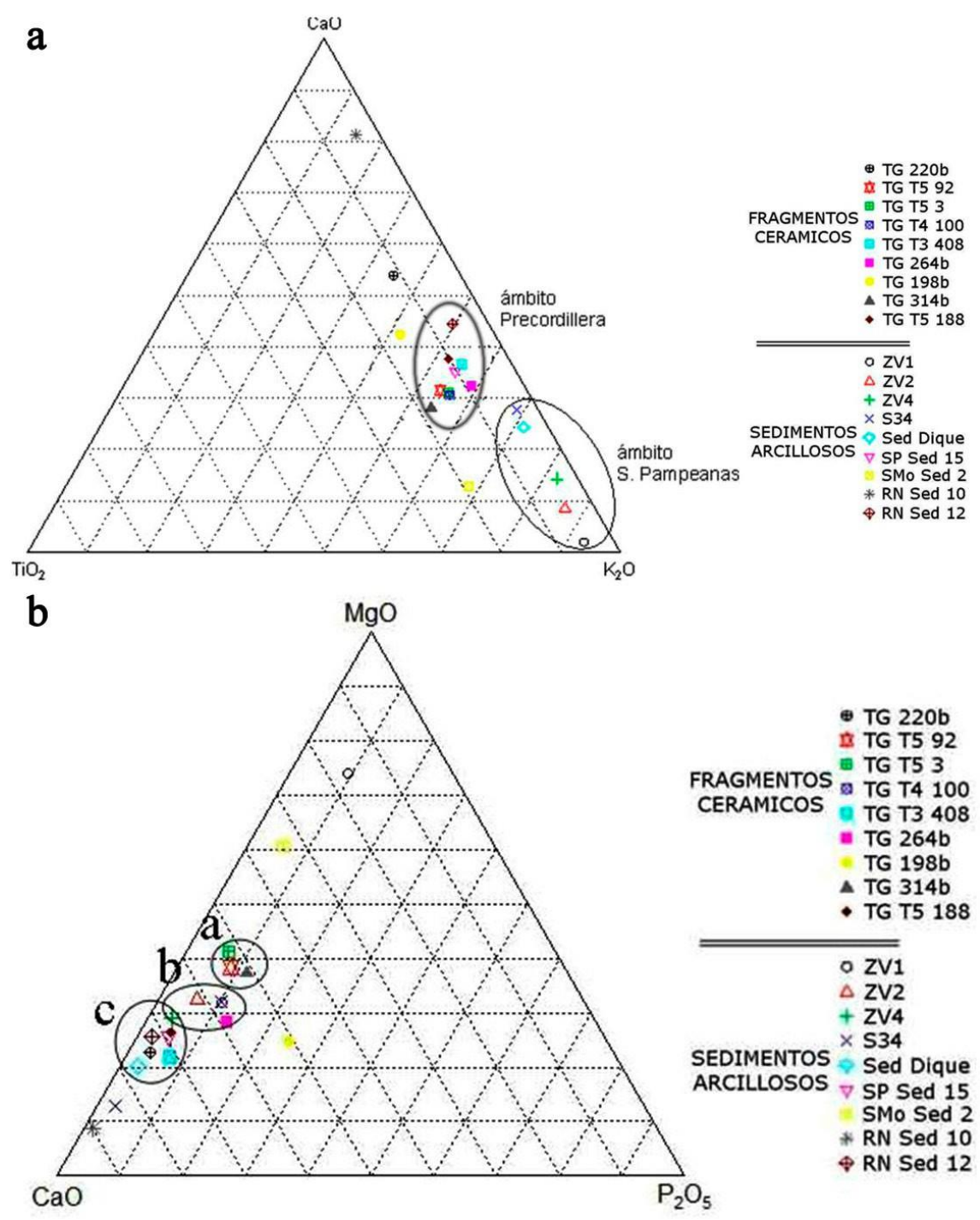

Figura 6: a) Diagrama triangular de relación $\mathrm{TiO} 2-\mathrm{CaO}-\mathrm{K}_{2} 0$. Se observa el agrupamiento de cerámicas y arcillas de Precordillera, y las muestras de Sierras Pampeanas de manera aislada. b) Diagrama triangular de relación $\mathrm{CaO}-\mathrm{MgO}-\mathrm{P}_{2} \mathrm{O}_{5}$. Se advierte un vínculo entre tiestos Sanagasta/Angualasto con tiesto Inca (a) y Aguada (c), y sedimentitas procedentes de Precordillera. Se reconoce uniformidad entre dos muestras Sanagasta/Angualasto con arcillas de Sierras Pampeanas (b).

回


Los resultados arqueométricos sugieren aspectos interesantes sobre las propiedades de las cerámicas y sedimentos estudiados, aunque se recuerda que se trata de un análisis preliminar y exploratorio sobre una muestra reducida. Se pudo obtener una primera identificación de la composición química, mineralógica y petrográfica de los diferentes sedimentos recuperados en el valle de Guandacol, así como un cierto conocimiento sobre las propiedades de las arcillas, algo hasta el momento no reconocido.

Desde los análisis químicos se advirtió una composición similar entre las arcillas y las cerámicas. Al relacionarlas parecería haber una tendencia del conjunto de piezas Sanagasta/Angualasto con muestras de Sierras Pampeanas y de Precordillera. Por su parte, las piezas Inca Provincial y Aguada también se relacionarían con este último sector. No sería el caso para la cerámica Diaguita Chileno Inca, la cual se discrimina del resto del registro.

A nivel petrográfico de arenas, también existiría una correspondencia geológica positiva con las muestras alfareras. Las rocas ígneas, sedimentarias y metamórficas reconocidas, esencialmente en las del área baja del valle y la Tambería, junto al Río Guandacol/La Troya, poseen características propias de ambientes fluviales. El arrastre de estos materiales producto de los procesos de erosión natural origina una selección submadura y madura de los clastos observados en las arenas (Jordan, Schrire \& Miller 1999:1335), los cuales son similares a los identificados previamente en las cerámicas, mayormente a las del estilo Sanagasta/Angualasto (Carosio 2018:168). Las leves variaciones entre las composiciones de las diferentes arenas estudiadas puede ser consecuencia de diferentes cuencas de aporte para cada uno de estos cursos hídricos del área, con afloramientos de rocas de formaciones variables. Con los restantes estilos cerámicos, si bien existen algunas similitudes con el perfil geológico del área, el vínculo es menos directo, dado por la ausencia en de algunos litoclastos de diferente origen, además del tamaño que muestran.

Estos datos químicos y litológicos iniciales podrían sugerir que parte del repertorio de piezas cerámicas de Guandacol estaría siendo fabricado con sedimentos locales y/o microregionales durante el periodo, lo cual implicaría la utilización de materiales semejantes durante largo tiempo, y así el traspaso y mantenimiento de ciertos procedimientos técnicos en la manufactura. No sería el caso de la cerámica Diaguita Chileno Inca, discriminada composicionalmente del registro y hallada escasamente en el sitio, lo que quizás sea un reflejo de su procedencia alóctona. De todas formas, se trata de muy pocas muestras analizadas, por lo que estas inferencias son sumamente inconclusas.

Desde el punto de vista tecnológico, en las arcillas y cerámicas se identificaron los minerales arcillosos illita, caolinita, y esmectitas, generalmente aptos para las producciones de cerámicas. Normalmente estas arcillas poseen altos contenidos de aluminio, un elemento primordial en las producciones alfareras al proveer un aumento en la resistencia mecánica de las cerámicas (Ginés et al. 1997).

La illita posee un IP menor que otras arcillas, perosuplasticidadaumentacuandodisminuye el tamaño del grano; la caolinita tiene buena maleabilidad, viscosidad y adsorción, ylas esmectitas óptimas propiedades de absorción y adsorción, aunque en el secado cerámico pierden volumen y se deforman, por lo que deben ser controladas (Bernal, Cabezas, Espitia, Mojica \& Quintero 2003:570-572). Sin embargo, mediante Límites de Atterberg determinamos que solo algunas arcillas poseen ligera plasticidad. Un IP es alto cuando tiene como resultado 30 o más, es bajo cuando es entre 15-30, ligeramente plástico de 3-15, y nulo de 0-3 (Sowers 1979). Por lo que éstas muestras, para ser bien trabajadas y utilizadas en una pasta, necesitarían la combinación con un/ unos sedimento/s más plásticos, además de un preparado cuidadoso de los mismos, 
realizando diversos procedimientos como el levigado, decantado, sedimentado y/o sobado.

En cuanto a las arenas, de emplearse materiales como los exhibidos, no habría un exhaustivo tratamiento previo a su incorporación a las pastas, especialmente para la alfarería Sanagasta/Angualasto, dado que poseen características generales muy similares. Para las cerámicas Aguada e Inca Provincial, con antiplástico de tamaño muy fino, habría un limpiado, colado y tamizado de los sedimentos antes de mezclarse con otra arcilla esencialmente plástica.

Finalmente, y vinculado con la cocción alfarera, los minerales arcillosos reconocidos permiten acercarse hacia las temperaturas de cocinado a la que fueron sometidos los recipientes (Maggetti 1982:127- 129; Linares, Huertas \& Capel Martínez 1983:482-485).

La presencia alta de potasio en la illita le comunica cierto poder fundente en el proceso de cocción, contribuyendo a que la pasta madure a una temperatura baja y controlada. Pierde agua en el intervalo 200$600^{\circ} \mathrm{C}$, se descompone a los $850^{\circ} \mathrm{C}$ y desaparece entre los $900^{\circ}-950^{\circ}$ C. Luego empieza la vitrificación del barro arcilloso, formándose espinelas, mullita y sillimanita. La caolinita pierde su agua estructural a los $500^{\circ} \mathrm{C}$, transformándose en metacaolinita, y a $\operatorname{los} 1000^{\circ} \mathrm{C}$ se originan dos nuevas fases: alúmina y mullita.

Finalmente, las esmectitas en general tienen su deshidroxilación entre los $500^{\circ}-700^{\circ} \mathrm{C}$, mantienen la estructura hasta $\operatorname{los} 800^{\circ}-900^{\circ}$ C y luego, en función de su composición mineralógica y variedad estructural, surge espinela, anortita, enstatita, cristobalita, cuarzo y cordierita, persistiendo hasta los $1300^{\circ} \mathrm{C}$.

En ninguna muestra cerámica analizadas hemos registrado estos minerales de formación, por lo que se preliminarmente que las cerámicas estudiadas no superaron los $950^{\circ}$ C. Este panorama es el que se sostiene para producciones de los mismos estilos en el ámbito regional (Rasmussen,
De La Fuente, Bond, Mathiesen. \& Vera 2012:1713-1714).

Para obtener mayor certeza en los resultados obtenidos es factible la realización y combinación de exámenes químicos elementales sobre una mayor cantidad de muestras cerámicas utilizando técnicas de alta precisión como los Análisis de Activación Neutrónica, ampliar los estudios de Difracción de Rayos X e incorporar otros como el Análisis Térmico Diferencial y Espectroscopia vibracional (FTIR-Raman) para reconocer temperaturas de cocción y transformaciones minerales, además de estudios experimentales sobre las arcillas y arenas recuperadas.

\section{CONCLUSIONES}

Las conclusiones de este trabajo indican que los datos composicionales reconocidos en las arcillas y arenas del valle de Guandacol son similares a los de las escasas muestras cerámicas analizadas del sitio, especialmente con el estilo Sanagasta/Angualasto. No todas las arcillas analizadas poseen cualidades óptimas de plasticidad, por lo que esfactible que para su uso se debe aplicar un accionar técnico significativo a dilucidar. Ello no implica que necesariamente estas arcillas hayan sido utilizadas para la manufactura de las piezas alfareras estudiadas. Por otro lado, a partir de los estudios de DRX se infiere que las temperaturas de cocción de las muestras cerámicas analizadas probablemente no superaron $\operatorname{los} 950^{\circ} \mathrm{C}$.

Esta información exploratoria debe considerarse como insuficiente, sin embargo constituye una base referencial para, a futuro, ampliar los datos composicionales mediante el estudio de un mayor aumento de muestras, fundamentalmente cerámicas de la Tambería y de sitios arqueológicos cercanos. Asimismo, es menester incorporar nuevas herramientas arqueológicas convencionales y arqueométricas para contrastar los resultados 
obtenidos y esclarecer el proceso de producción alfarera que se desarrolló en los últimos siglos prehispánicos de Guandacol.

El conocer la composición de alfarerías y materias primas, y el comportamiento geotécnico de arcillas permiten, en conjunto, comenzar a acercarse a un gran abanico de información sobre la posible procedencia de fuentes de materias primas, la potencialidad para su utilización, y sobre diferentes aspectos tecnológicos alfareros.

\section{AGRADECIMIENTOS}

A la comunidad de Guandacol y al gobierno de la provincia de La Rioja. A los Dres. J. R. Bárcena, Daniel Sales, Ernesto Perino y Daniel Codega; a los que colaboraron en trabajos de laboratorio en el Depto. de Geología (UNSL), Flavia Lorca y Matías Merlo; y a aquellos miembros de la Unidad de Antropología (INCHUSA-CONICET) y Facultad de Filosofía y Letras (UNCUYO) que participaron en las tareas de campo, Lourdes Iniesta, Juan Pablo Aguilar, Cristian Tivani y Vanina Terraza. A los evaluadores, por sus sugerencias. El relevamiento arqueológico, la recuperación del material cerámico y su estudio fueron posible gracias a subsidios de los proyectos PICT ANPCyT 2007 01529, PIP CONICET 112-200801- 02957, y 06/G475, 06/ G639 y 06/G714 de la SeCyT (UNUCYO), dirigidos en todos los casos por J. R Bárcena y en el cual el primer autor formó parte. Este análisis fue realizado en el marco de las Becas Doctoral y Posdoctoral del CONICET del primer autor, dirigidas por J.R. Bárcena y Amancay Martínez. Lo expresado es de exclusiva responsabilidad de los autores.

\section{REFERENCIAS BIBLIOGRÁFICAS}

Albero Santacreu, D. (2014). Materiality, Techniques and Society in Pottery Production. The Technological Study of Archaeological Ceramics through Paste Analysis. Warsaw/Berlin: De Gruyter Open Ltd.

Arnold, P. J. 1991. Domestic ceramic production and spatial organization: $a$ Mexican case study in ethnoarchaeology. Cambridge: Cambridge University Press.

Arnold, D. (2005). Linking Society with the Compositional Analyses of Pottery: A Model from Comparative Ethnography. EnA.Livingstone Smith, D. Bosquet, \& R. Martineau (eds.). Pottery Manufacturing Processes: Reconstitution and Interpretation (pp. 21-47). Oxford: British Archaeological Reports.

Balfet, H. (1991). Des chaînes opératoires, pour quoi faire? En H. Balfet (org.). Observer l'action technique deschaînes opératoires, pour quoi faire? (pp. 11-19). Paris: CNRS.

Bárcena, J. R. (2010). Investigaciones arqueológicas en la Tambería de Guandacol (Departamento Felipe Varela, La Rioja). En J. R. Bárcena (ed.). Aportes de las IV Jornadas Arqueológicas Cuyanas (pp. 121-181). Monografías XAMA 2. Mendoza: INCIHUSA-CONICET.

Bernal, I., Cabezas, H., Espitia, C., Mojica, J. \& Quintero, J. (2003). Análisis próximo de arcillas para cerámica. Revista de la Academia Colombiana de las Ciencias, 27 (105), 569-578.

Bertolino, S. \& Fabra, M. (2003). Provenance and ceramic technology of pot sherds from ancient Andean cultures at the Ambato valley, Argentina. Applied clay science, 24 (1-2), 21-34.

Boman, E. (1927-1932). Estudios arqueológicos riojanos. Anales del Museo Nacional de Historia Natural, 
35 (72), 1-341.

Callegari, A. \& Gonaldi, M. (2006). Análisis comparativo de procesos históricos durante el Período de Integración Regional en valles de la provincia de La Rioja. Chungará, 38 (2), 197-210.

Callegari, A. \& Gonaldi, M. (2007-2008). Guandacol. Estructuras arquitectónicas tardías del sudoeste de la Provincia de La Rioja. Arqueología, 14, 173-187.

Carosio, S. A., Iniesta, M. L. \& Bárcena, J. R. (2011). Análisis ceramológicos de la Tambería de Guandacol (Dpto. Felipe Varela, Provincia de La Rioja). Avances para la conformación de grupos de referencia y el conocimiento tecnomorfológico de recipientes. Comechingonia Virtual, 5 (2), 98-128. Recuperado de http://132.248.9.34/ hevila/Comechingoniavirtual/2011/ vol5/no2/1.pdf

Carosio, S. A. (2015). Investigaciones ceramológicas en el oeste de la Provincia de La Rioja: La Tambería de Guandacol y el periodo de los Desarrollos Regionales (1000- 1470 $A D)$ (Tesis doctoral inédita). Facultad de Filosofía y Humanidades, Universidad Nacional de Córdoba, Córdoba, Argentina.

Carosio, S. A. \& Iniesta, M. L. (2017). Una aproximación a las trayectorias estilísticas cerámicas del valle de Guandacol (Provincia de La Rioja): continuidades y rupturas entre los siglos XIII y XVIII. Revista del Museo de Antropología, Suplemento Especial 1, 123-128.

Carosio, S. A. (2018). Prácticas de manufactura cerámica en el oeste riojano durante el Periodo Tardío (ca. siglos XIII-XVII AD). Aportes desde los estudios petrográficos sobre el estilo Sanagasta/Angualasto de la Tambería de Guandacol. Comechingonia, 22 (1), 151-183.

Clop, X. (2008). L'estudi de les ceràmiques prehistòriques des del'arqueometria. Cota Zero, 23, 25-37.
Compton, R. (1962). Geología de Campo. Buenos Aires: Editorial Pax.

Cremonte, B. \& Botto, I. (2009). Unas vasijas especiales de contextos tardíos del Noroeste Argentino. Manufactura de los Pucos Bruñidos. Estudios Atacameños, 37, 63-77.

Cremonte, B. \& Bugliani, F. (2006-2009). Pasta, forma e iconografía. Estrategias para el estudio de la cerámica arqueológica. Xama, 19-23, 239-262.

De la Fuente, N. (1973). El Yacimiento Arqueológico de Guandacol, Provincia de la Rioja. Revista del Instituto de Antropología, 4, 151-167.

De la Fuente, G., Ratto, N., Toselli, G. \& Plá, R. (2008). Producción y tecnología cerámica: especialización y estandarización a través de la aplicación de INAA, petrología cerámica y radiografías de rayos Xen el sitio arqueológico Batungasta, Noroeste Argentino (Valle de Abaucán-Dpto. Tinogasta-CatamarcaArgentina). En Austral A. \& M. Tamagnini (comp.). Problemáticas de la Arqueología Contemporánea, Tomo II (pp. 135-143). Río Cuarto: Universidad Nacional de Río Cuarto.

Debenedetti, S. (1917). Investigaciones en los valles preandinos de la provincia de San Juan. Nueva edición de la Revista de la Universidad de Buenos Aires, XXXII, 61-99, 226-256, XXXIV, 122167, 339-405.

Estévez Morales, J. A. (1998). Aplicación de la metodología arqueométrica al estudio de cerámicas: teoría y desarrollo práctico: el caso de un grupo de cerámicas localizadas en Mérida. Mérida, excavaciones arqueológicas, 4, 583-609.

Folk, R. (1951). Stages of textural maturity in sedimentary rocks. Journal of Sedimentary Petrology, 21, 127-130.

Furque, G. (1963). Descripción geológica de la Hoja 17b-Guandacol Provincia de La Rioja-Provincia de San Juan. Boletín, 92, 1-104. 
García Rosselló, J. (2011). Modelado, aprendizaje y espacio social: una reflexión desde la tecnología cerámica. Werkén, 14, 63-74.

Ginés, F., Feliu, C., García-Ten, J. \& Sanz, V. (1997). Análisis de los métodos tradicionales utilizados para evaluar la plasticidad. Boletín de la Sociedad Española de Cerámica y Vidrio, 36(1), 25-30.

Gentili, C. (1972). Descripción geológica de la Hoja 17c, Cerro Rajado - Provincias de San Juan y La Rioja. Boletín, 131, 1-62.

Glascock, M. (1992). Neutron Activation Analysis. Chemical Characterization of Ceramic Pastes in Archaeology. Monographs in World Archaeology, 7, 1-11.

González A. \& Pérez, J. (1972). Argentina indígena. Vísperas de la conquista. Buenos Aires: Paidós.

Iniesta, M. L. \& Bárcena, J. R. (2014). Investigaciones arqueológicas sobre las sociedades tardías del valle de Guandacol (Departamento Felipe Varela, oeste de La Rioja): Espacio, estilos tecnológicos cerámicos y cronología. Arqueología, 20, 61-82.

Jordan, S. C., Schrire, C. \& Miller, D. (1999). Petrography of locally produced pottery from the Dutch colonial Cape of Good Hope, South Africa. Journal of Archaeological Science, 26, 13271337.

Lechtman, H. (1977). Style in technology some early thoughts. En H. Lechtman, H. \& R. Merril (eds.). Material Culture: Styles, Organization and Dynamics of Technology (pp. 3-20). Minnesota: American Ethnological Society.

Lemonnier, P. (1992). Elements for an anthropology of technology. Anthropological Papers 88. Museum of Anthropology, University of Michigan. Michigan: Ann Arbor.

Leroi-Gourham, A. (1964). Le geste et la parole I, Technique et langage. Paris:
Albin Michel.

Linares, J.; Huertas, F. \& Capel Martínez, J. (1983). La arcilla como material cerámico. Características y comportamiento. Cuadernos de Prehistoria de la Universidad de Granada, 8, 479-490.

Maggetti, M. (1982). Phase analysis and its significance for technology and origin. En Olin J. \& A. Franklen (eds). Archaeological Ceramics (pp. 121133). Washington D.C.: Smithsonian Institution Press.

Mas Pérez, F. (1985). Estudio de arcillas de interés cerámico de la provincia de Alicante (Tesis Doctoral inédita), Universidad de Alicante, Alicante, España.

Michieli, C. (2007). Población prehistórica e histórica de Iglesia (Provincia de San Juan). TEFROS, 5 (1), pp 1-23.

Munsell Color. (1994). Munsell Soil Color Charts. New York: Macbeth Division of Kollmorgen Instruments Corporation.

Neff, H. (1992). Chemical Characterization of Ceramic Pastes in Archaeology. Monographs in World Archaeology, (7). Wisconsin: Prehistory Press.

Orton, C., Tyers, P. \& Vince, A. (1997). La Cerámica en Arqueología. Barcelona: Crítica.

Páez, C. \& Plá, R. (2015). Producción local de objetos cerámicos durante los periodos Tardío e Inca en el Valle de Tafí (Tucumán, Argentina). Chungara, 47 (3), 429-440.

Puente, V., Plá, R. \& Invernizzi, R. (2014). La alfarería del Tardío Prehispánico del Valle del Bolsón (Catamarca, Argentina): ¿producción local o alóctona?. Revista del Museo de Antropología, 7 (1), 65-78.

Raith, M.; Raase, P.\& Reinhardt, J. (2012). Guía para la Microscopía de Minerales en Lámina Delgada. Bonn: University of Bonn.

Rasmussen, K., De La Fuente, G., Bond, A., Mathiesen, K. \& Vera, S. (2012). 
Pottery firing temperatures: a new method for determining the firing temperature of ceramics and burnt clay. Journal of Archaeological Science, 39, 1705-1716.

Rice, P. (1987). Pottery analysis. A sourcebook. Chicago: University of Chicago Press.

Sanhuesa, L. (2006). El concepto de estilo tecnológico y su aplicación a la problemática de las sociedades alfareras tempranas de Chile Central. En D. Jackson, D. Salazar \& A. Troncoso (eds.). Puentes hacia el pasado: reflexiones teóricas en Arqueología (pp. 157-174). Santiago: Serie Monográfica de la Sociedad Chilena de Arqueología.

Sillar, B. \& Tite, M. (2000). The Challenge of Technological Choices for Materials Science approaches in Archaeology. Archaeometry, 42 (1), 2-20.

Singer, F. \& Singer, S. (1971). Cerámica Industrial. Bilbao: URMO.

Sowers, G. (1979). Introductory Soil Mechanics and Foundations. Macmillan, New York.

Stoltman, J. (1989). A quantitative approach to the petrographic analysis ceramic thin sections. American Antiquity, 54, 147-160.

Tarragó, M. (2000). Chacras y pukara. Desarrollos sociales tardíos. En M. Tarragó (comp.). Nueva Historia Argentina 1: Los pueblos originarios y la conquista (pp. 257-300). Barcelona: Sudamericana.

Tripaldi, A. \& Limarino, C. (2008). Ambientes de interacción eólicafluvial en valles intermontanos: ejemplos actuales y antiguos. Latin American Journal of Sedimentology and Basin Analisis, 15 (1), 43-66. 